\title{
GESTÃO DE COMPETÊNCIAS PROFISSIONAIS NA FORMAÇÃO DE ADMINISTRADORES
}

\author{
Maria de Lourdes Severo Regio*; Vitor Francisco Schuch JR.** \\ Clandia Maffini Gomes***; Jordana Marques KneipP****
}

Recebido: 18 maio $2012 \quad$ Aprovado: 22 ago. 2012

\author{
*Universidade Federal de Santa Maria. Santa Maria, RS, Brasil. Contato: biasr@cpd.ufsm.br. \\ **Universidade Federal de Santa Maria. Santa Maria, RS, Brasil. Contato: vfschuch@uol.com.br \\ ***Universidade Federal de Santa Maria e a UNIPAMPA. Santa Maria, RS, Brasil. Contato: clandia@ \\ smail.ufsm.br \\ **** Universidade Federal de Santa Maria. Santa Maria, RS, Brasil. Contato: jordanakneipp@yahoo.com.br
}

Resumo: A avaliação da qualidade de um curso superior de graduação envolve, necessariamente, a identificação do perfil profissional dos egressos. A primeira pesquisa realizada com os egressos do Curso de Graduação em Administração da Universidade Federal de Santa Maria (UFSM), objeto deste estudo, foi efetuada por Schuch Jr. (1976). Esta pesquisa foi retomada agregando novas dimensões de análise, visando a abordar o desenvolvimento de competências conforme estabelecem as Diretrizes Curriculares Nacionais (DCNs). O estudo foi realizado com egressos formados no período de 2005 a 2009. Com a realização da pesquisa, buscou-se conhecer a realidade profissional, identificar as competências profissionais exigidas e a contribuição do curso em termos de formação acadêmica para o desenvolvimento das competências. A estratégia metodológica utilizada caracterizou-se como um estudo de caso descritivo e quantitativo. A coleta de dados foi realizada por meio da aplicação de dois tipos de questionários estruturados, com questões fechadas e abertas envolvendo uma amostra formada por 121 egressos A aplicação da técnica de análise fatorial permitiu identificar as principais competências exigidas pelo mercado profissional: padrões e valores, adaptação e negociação, conhecimento e técnico-profissional. Os resultados sugerem que as expectativas propostas pelas DCNs estão sendo plenamente desenvolvidas pelo Curso de Administração da UFSM.

Palavras-chave: Egressos em administração. Competências do administrador. Formação de administradores.

\section{MANAGEMENT SKILLS IN THE TRAINING OF ADMINISTRATORS}

Abstract: The evaluation of quality of a bachelor's program necessarily involves the identification of graduated professionals' profiles. The first research conducted with graduates of Business Administration Bachelor's Program of the Federal University of Santa Maria (UFSM), object of this study, was conducted by Schuch Jr. (1976). This research was retaken and new dimensions of analysis were added, aiming to approach the development of competences according to what is established by the National Curricular Guidelines. The study was conducted with bachelors graduated between 2005 and 2009. Through this research it was intended to know the professional reality, to identify the professional competences required and the contribution of the program in terms of academic training to the development of competences. The methodological strategy used was a descriptive and quantitative case study. Data collection was conducted through the application of two kinds of structured questionnaires, with closed and open questions, involving a sample of 121 graduates. The application of factorial analysis technique allowed the identification of the main competences demanded by the professional market: standards and values, adaptation and negotiation, knowledge and technician-professional. The results suggest that the expectations proposed by the National Curricular Guidelines are thoroughly developed by the Business Administration Bachelor's Program of Federal University de Santa Maria.

Key words: Business administration graduates. Administrator's competences. Administrator's academic training. 


\section{INTRODUÇÃO}

A qualificação do ensino de Administração exige uma avaliação profunda da formação que está sendo desenvolvida. Muito pouco tem sido feito no Brasil. São poucos os estudos que discutem esta problemática. Uma avaliação efetiva de um curso superior de graduação envolve, necessariamente, a análise de seus egressos. São eles, no seu exercício profissional e na complexidade da vida social, que podem melhor avaliar o quanto o curso contribui para o desenvolvimento das competências que o currículo pretendia, bem como indicar suas expectativas de educação continuada para que as Instituições de Ensino Superior (IES) possam melhor ajustar suas ofertas de cursos. Muito embora reconhecendo a importância e sendo a relação com egressos uma dimensão da avaliação de cursos e instituições, são muito poucos os cursos que mantêm banco de dados de egressos e promovem o relacionamento com estes.

A realização de pesquisa com egressos, constituindo e mantendo banco de dados periodicamente realimentado, com metodologias de fácil implantação, pode ser um estímulo à adoção pelas instituições. Tais estudos podem contribuir com a qualificação do ensino na medida em que promovem a discussão em torno da avaliação da aprendizagem nos cursos. O Curso de Graduação em Administração da Universidade Federal de Santa Maria (UFSM), objeto deste estudo, já teve a realidade de seus egressos pesquisada. O estudo anterior, Formação de Administradores e Mercado de Trabalho, foi elaborado por Vitor Francisco Schuch Junior em 1976. Na ocasião, foi identificada a realidade de mercado de trabalho dos egressos, envolvendo colocação, tipo de função exercida, perfil das organizações nas quais atuavam, vínculos de propriedade e parentesco e a relação destas variáveis com o aproveitamento acadêmico quando estudantes. Após 35 anos da realização daquela primeira pesquisa, elaborada por Schuch Junior (1976), este estudo propõe-se a retomar o mesmo esforço para o conhecimento atualizado da realidade do mercado de trabalho de seus 1976 egressos $^{1}$, sendo que 1546 são do Curso de Administração Diurno e 430 do Noturno. Ampliado, o estudo poderá proporcionar uma avaliação mais consistente da formação que o Curso vem desenvolvendo ao longo desses anos e de sua inserção no mercado profissional. Com o passar dos anos, a formação de administradores foi se transformando com a proliferação das habilitações específicas no currículo dos cursos. Alguns cursos, dentre eles o da UFSM, mantiveram, entretanto, seu currículo generalista. A discussão sobre a forma-

1 Informações obtidas no CPD (Centro de Processamento de Dados - UFSM) dos registros no Sistema SIE (Sistema de Informações para o Ensino) em Dezembro de 2010 
ção generalista, contrapondo-se à de especialista, tomou conta das discussões curriculares em todo o país. Foi finalmente encerrada com a aprovação, no Conselho Nacional de Educação (CNE), das Diretrizes Curriculares Nacionais (DCN) para os Cursos de Graduação em Administração, a Resolução CNE/ CES 4/2005 que determinou uma formação generalista.

Com base nas Diretrizes Curriculares Nacionais (DCN), o resultado esperado com a realização do presente estudo foi verificar se o curso contribui para o desenvolvimento das competências que o currículo pretendia, sugeridas pelo CNE, para os egressos do Curso de Graduação em Administração de Empresas.

\section{O PAPEL DOS EGRESSOS NA EDUCAÇÃO SUPERIOR DO BRASIL}

A história do ensino e da profissionalização da Administração no Brasil é bastante recente, pouco mais de cinco décadas se comparado aos EUA, onde os primeiros cursos na área se iniciaram, no final do século XIX. Segundo Castro (1981), o primeiro curso de Administração nos EUA foi criado com a fundação da Wharton School, por Joseph Warton, em 1881. Para Andrade (1997, p. 1), a história do Ensino Superior de Administração vem sendo construída nos EUA, há mais de um século. O mesmo autor afirma que, quando se iniciava o ensino de Administração no Brasil, nos EUA já se formavam cerca de 50 mil bacharéis, 4 mil mestres e 100 doutores, por ano. Segundo Wood Jr. (2002), a partir da segunda metade do século XX, ocorreu um crescimento dos programas de $\mathrm{PhD}$ e do Master in Business Administration - MBA, e as Escolas de Administração acabaram se transformando em produto de exportação. Martins (1989) aponta que o movimento para a formação profissional do administrador no Brasil começou a se definir na década de quarenta, quando a economia brasileira deixou de ser essencialmente agrária e iniciou-se a expansão dos setores industriais e de serviços, acentuando a necessidade de mão de obra qualificada.

Couvre (1991) afirma que o ensino de Administração está relacionado ao processo de desenvolvimento do país e salienta que a criação de cursos de Administração intensificou-se após a década de 1960, com a expansão do ensino superior. Segundo Schuch Júnior (1976), foi em 1954, com a criação da EAESP (Escola de Administração de Empresas de São Paulo), que surgiu o primeiro currículo de Administração, influenciando, assim, as instituições de ensino superior, que passariam a oferecer o curso no país. De acordo com o Censo do Ensino Superior, realizado pelo Inep, em 2008, a expansão das Instituições de Ensino Superior (IES) em Administração, no Brasil, é expressiva a partir da 
segunda metade da década de 1990, chegando, em 2008, a 2.252 IES, envolvendo 872.265 alunos matriculados, e a tendência é de continuar aumentando, considerando o crescimento econômico e a perspectiva da sociedade brasileira. A Tabela 1 apresenta os dados, revelando, de um modo geral, o contexto histórico dos cursos de Administração no País.

Tabela 1 - Resumo da evolução dos cursos de Administração no Brasil

\begin{tabular}{|c|c|c|c|c|}
\hline ANO & IES & $\begin{array}{r}\text { Matrículas em ADM } \\
\text { (Presenciais) }\end{array}$ & $\begin{array}{r}\text { Concluintes em ADM } \\
\text { (Presenciais) }\end{array}$ & $\begin{array}{r}\text { Concluintes } \mathrm{x} \\
\text { Matrículas }\end{array}$ \\
\hline $\begin{array}{l}\text { Antes de } \\
1960^{1}\end{array}$ & 2 & $\mathrm{~N} / \mathrm{l}$ & $\mathrm{N} / \mathrm{I}$ & \\
\hline 1967 & 31 & $\mathrm{~N} / \mathrm{l}$ & $\mathrm{N} / \mathrm{I}$ & \\
\hline 1970 & 164 & 66829 & 5.276 & $7,9 \%$ \\
\hline 1980 & 247 & 134.742 & 21.746 & $16,1 \%$ \\
\hline 1990 & 320 & 174.330 & 22.394 & $12,8 \%$ \\
\hline $1997^{2}$ & 900 & 237.671 & 29.045 & $12,2 \%$ \\
\hline 1998 & 973 & 257.743 & 31.666 & $12,3 \%$ \\
\hline 1999 & 1.097 & 286.454 & 2.969 & $1,0 \%$ \\
\hline $2000^{3}$ & 1.180 & 339.363 & 35.726 & $10,5 \%$ \\
\hline 2001 & 1.391 & 404.771 & 39.231 & $9,7 \%$ \\
\hline 2002 & 1.637 & 494.390 & 54.748 & $11,1 \%$ \\
\hline 2003 & 1.859 & 578.020 & 64.910 & $11,2 \%$ \\
\hline 2004 & 2.013 & 643.635 & 88.718 & $13,8 \%$ \\
\hline 2005 & 2.165 & 709.301 & 109.840 & $15,5 \%$ \\
\hline 2006 & 2.270 & 775.201 & 123.816 & $16,0 \%$ \\
\hline 2007 & 2.281 & 805.559 & 121.846 & $15,1 \%$ \\
\hline 2008 & 2.252 & 872.265 & 141.498 & $16,2 \%$ \\
\hline
\end{tabular}

Fonte: INEP. Sinopse estatística da educação superior. Brasília, 2009.

Para Schuch Junior (1976), a ideia do ensino da Administração e da profissionalização das atividades administrativas desenvolveu-se e impregnou os ambientes acadêmicos, empresariais e o serviço público. Este movimento já tinha motivado a criação de vários cursos superiores, quando suas lideranças conseguiram despertar a atenção do Poder Legislativo Nacional para a gravidade da questão, obtendo, finalmente, em 9 de setembro de 1965, a regulamentação da nova profissão de Administrador, conforme ficou designado pela Lei 4.769.

2 Dados obtidos do site do Conselho Federal de Administração (CFA). Disponível em: < http://www.cfa. org.br/arquivos/index.php>.

3 Para se obter o total de cursos de Administração de 1999 a 1997, foram englobados três cursos: Administração, Administração Rural e Administração de Recursos Humanos. Fonte: INEP. Sinopse Estatística da Educação Superior, 2006.

4 Para se obter o total de cursos de Administração de 2008-2000, foram utilizados dois grupos: Comércio e Administração (cursos gerais) 


\section{COMPETÊNCIAS PARA A FORMAÇÃO DO ADMINISTRADOR}

Para um melhor entendimento sobre o tema competência, faz-se necessário analisar a natureza da competência individual, visto que é nos indivíduos que residem o conhecimento, as atitudes e as habilidades. A expressão competência tem sido empregada com diversos sentidos e significados nos últimos anos e, de acordo com Fleury e Fleury (2001), muitas são as discussões relacionadas ao tema competência, seu desenvolvimento, sua gestão, tanto no nível da competência do indivíduo quanto das organizações (core competences), assim como dos países nos sistemas educacionais e formação de competências.

As grandes correntes teóricas, ao abordar o tema competência, são a americana, representada pelos autores McClelland (1973), Boyatzis (1982), Spencer e Spencer (1993), McLagan (1996), e a francesa, que traz Le Boterf (1993) e Zarifian (1996) como principais representantes (FLEURY; FLEURY, 2007; DUTRA, 2008).

Assim, diversos autores conceituam o termo competência, entre eles McClelland (1973), que representa o pensamento dos autores americanos, ao destacar a abordagem da competência tendo como um dos focos o indivíduo no trabalho, ou seja, é determinada a partir de comportamentos que geram o melhor desempenho. Esse mesmo autor define competência como um conjunto de qualificações ou características subjacentes à pessoa, aceitando que ela realize uma tarefa em uma determinada situação.

Como representante da corrente francesa, Le Boterf (2003) destaca que, na década de 70, a definição de competência tinha como domínio a noção de qualificação enquanto que o conceito de competência que acompanha o profissionalismo teve seu auge no decorrer dos anos 80 .

De acordo com Zarifian (2003, p. 137), o conceito de competências está baseado em três elementos:

Competência é a tomada de iniciativa e responsabilidade do indivíduo em situações profissionais com as quais ele se defronta. Competência é uma inteligência prática das situações, que se apóia em conhecimentos adquiridos e os transforma à medida que a diversidade das situações aumenta. Competência é a faculdade de mobilizar redes de atores em volta das mesmas situações, de compartilhar desafios, de assumir áreas de responsabilidade.

Fleury e Fleury (2007, p. 30) definem a competência como "um saber agir responsável e reconhecido, que implica mobilizar, integrar, transferir conhecimentos, recursos, habilidades, agregando valor econômico à organização e valor social ao indivíduo". 
Conforme Zarifian (2001), é possível identificar cinco classificações de competências em uma organização:

- Competências sobre processos: os conhecimentos sobre processos de trabalho;

- Competências técnicas: conhecimentos específicos sobre o trabalho que deve ser realizado;

- Competências sobre a organização: saber organizar os fluxos de trabalho;

- Competências de serviço: aliar competência técnica à pergunta: Qual o impacto que este produto ou serviço terá sobre o consumidor final?

- Competências sociais: saber ser, incluindo atitudes que sustentam os comportamentos das pessoas.

Já para os autores Fleury e Fleury (2001), as competências são divididas em três blocos que compreendem as relações do indivíduo com a empresa em uma perspectiva sistêmica. No primeiro bloco, denominado competências de negócios, estão presentes as competências relacionadas à compreensão do negócio em função de seus objetivos na relação do mercado, clientes e competidores, assim como do contexto político e social mais amplo. No segundo, são apresentadas as competências técnico-profissionais características de determinada ocupação, atividade ou operação. No terceiro, estão inseridas as competências sociais que, na visão dos mesmos autores, são imprescindíveis para interagir com as pessoas, entre as quais se destacam a comunicação, a negociação, a mobilização para mudança, a sensibilidade cultural e o trabalho. Agregam-se a esta discussão as contribuições de Nunes e Barboza (2003), ao mencionarem que o debate do conceito de competências passa pelo campo da educação, surgindo no bojo das discussões o sistema educacional frente às exigências de competitividade, produtividade e inovação do sistema produtivo.

Perrenoud (1999) define a competência individual como a capacidade de agir eficazmente em um determinado tipo de situação, apoiada em conhecimentos, mas sem limitar-se a eles. A ampliação deste conceito para o campo da educação passa a considerar o desenvolvimento de competências como um dos princípios norteadores das Diretrizes Curriculares Nacionais, de modo a conceituar competência profissional como sendo "a capacidade de mobilizar, articular e colocar em ação valores, conhecimentos e habilidades necessários 
para o desempenho eficiente e eficaz de atividades requeridas pela natureza do trabalho" (BRASIL, 1999, p. 2).

Concluindo este item, percebe-se que a literatura aponta diversos tipos de competências, mas este estudo está relacionado mais especificamente com a formação profissional dos egressos do curso de Graduação em Administração.

Trazendo esta discussão para a área da Administração, acrescentam-se as competências desejadas do egresso do Curso de Graduação em Administração, conforme institui a Resolução CNE/CES 4/2005, em seu artigo 4:

Art. 4ํ- O Curso de Graduação em Administração deve possibilitar a formação profissional que revele, pelo menos, as seguintes competências e habilidades:

I - reconhecer e definir problemas, equacionar soluções, pensar estrategicamente, introduzir modificações no processo produtivo, atuar preventivamente, transferir e generalizar conhecimentos e exercer, em diferentes graus de complexidade, o processo da tomada de decisão; II - desenvolver expressão e comunicação compatíveis com o exercício profissional, inclusive nos processos de negociação e nas comunicações interpessoais ou intergrupais;

III - refletir e atuar criticamente sobre a esfera da produção, compreendendo sua posição e função na estrutura produtiva sob seu controle e gerenciamento;

IV - desenvolver raciocínio lógico, crítico e analítico para operar com valores e formulações matemáticas presentes nas relações formais e causais entre fenômenos produtivos, administrativos e de controle, bem assim expressando-se de modo crítico e criativo diante dos diferentes contextos organizacionais e sociais;

$\mathrm{V}$ - ter iniciativa, criatividade, determinação, vontade política e administrativa, vontade de aprender, abertura às mudanças e consciência da qualidade e das implicações éticas do seu exercício profissional; VI - desenvolver capacidade de transferir conhecimentos da vida e da experiência cotidianas para o ambiente de trabalho e do seu campo de atuação profissional, em diferentes modelos organizacionais, revelando-se profissional adaptável;

VII - desenvolver capacidade para elaborar, implementar e consolidar projetos em organizações; e

VIII - desenvolver capacidade para realizar consultoria em gestão e administração, pareceres e perícias administrativas, gerenciais, organizacionais, estratégicos e operacionais.

Lacombe e Heilborn (2002) postulam que a construção da carreira profissional e a relação do indivíduo com seu trabalho tornaram-se temas centrais no exercício da atividade do administrador. Segundo a visão da autora, as 
organizações vêm reformulando as suas práticas e princípios orientadores da gestão de pessoas, e essas transformações no processo de gestão têm ocasionado mudanças no desenvolvimento das carreiras organizacionais.

De acordo com Lacombe e Heilborn (2002, p. 2):

[...] a reflexão sobre a relação das pessoas com o seu trabalho e sobre os conceitos e mecanismos relacionados ao desenvolvimento das carreiras no contexto organizacional proporciona ao administrador (a) a possibilidade de atender às demandas do mercado, se posicionar e de transitar no mercado de trabalho e (b) as condições para o exercício de uma gestão mais humanizada, com foco nas pessoas. E, assim sendo, as percepções sobre a carreira e o trabalho indicarão como o administrador entende a sua própria relação com o trabalho (e das demais pessoas) como entende a dinâmica da gestão no contexto organizacional atual.

Ao estudar a relação entre o desempenho da carreira no mercado de trabalho e a escolha profissional dos jovens, Bartalotti e Menezes Filho (2007) mencionam que o processo de escolha de uma determinada carreira relaciona-se com uma alocação ótima de risco e retorno entre cada carreira. Estes mesmos autores acrescentam que fatores mais subjetivos também influenciam as escolhas de carreira entre pessoas, como, por exemplo, o status que uma determinada carreira proporciona aos profissionais. Além destes fatores, no entender dos autores, a escolha também pode ocorrer em função da concorrência de admissão para a universidade e em função das características individuais das pessoas, que podem ter impacto decisivo nas escolhas da carreira profissional.

Bitencourt e Klein (2007) mencionam que o contexto sócio-político, econômico e cultural tem afetado o desenvolvimento das empresas e das pessoas. Neste sentido, manter-se atualizado para enfrentar os desafios, como a capacidade de gerenciar as mudanças, de mobilizar as pessoas, de tomar decisões ágeis e assertivas, de gerir recursos e processos é uma forma de se obter vantagem competitiva.

Este cenário de transformações, ainda segundo os mesmos autores, faz com que as organizações e as pessoas persigam estratégias de gestão e de carreira como uma forma de adequação a esse mercado em constante mudança.

Uma das formas de mensurar a adequação dos profissionais graduados às exigências do mercado é através da avaliação do curso de graduação, de modo a verificar o quanto o processo de ensino-aprendizagem contribuiu para o desenvolvimento das competências necessárias para o desempenho da profissão. Lousada e Martins (2005) sinalizam para a importância do planejamento e 
desenvolvimento de sistemas de acompanhamento de egressos como um dos mecanismos capazes de promover a contínua melhoria do processo de ensinoaprendizagem.

Espera-se que o aluno que conclua o curso de graduação apresente as competências desejadas para o Curso de Graduação em Administração. Dessa forma, questões referentes à reformulação dos projetos pedagógicos dos cursos de graduação em Administração têm sido enfatizadas em diferentes oportunidades (GODOY et al., 2005), o que torna a discussão sobre a aquisição efetiva das competências sugerida nas diretrizes pertinente para a compreensão do fato e para a consequente implantação de ações, ou manutenção das atividades desenvolvidas pelas IES.

A pesquisa aqui proposta, neste item competências, está baseada em um estudo feito por Godoy et al. (2005) na formação de administradores, em uma IES, frente às competências e habilidades sugeridas pelas diretrizes curriculares nacionais para o curso de Administração. Diante desta perspectiva e frente às demandas por novas atitudes por parte dos profissionais, emerge a preocupação com o desenvolvimento de competências que, segundo Bitencourt (2005), consistem em:

Um processo contínuo e articulado de formação e desenvolvimento de conhecimentos, habilidades e atitudes em que o indivíduo é responsável pela construção e consolidação de suas competências (autodesenvolvimento) a partir da interação com outras pessoas no ambiente de trabalho, familiar e/ou em outros grupos sociais (escopo ampliado), tendo em vista o aprimoramento de sua capacitação, podendo, dessa forma, adicionar valor às atividades da organização, da sociedade e a si próprio (auto-realização) (p. 24).

Para Zarifian (1996), a gestão de competências refere-se ao conjunto de práticas tradicionais que estabelecem as necessidades ou qualidades necessárias a um indivíduo na ocupação de um posto de trabalho ou na conquista de um emprego. A definição de competências, segundo a concepção de Dutra, Hipólito e Silva (1998), relaciona-se com um conjunto de qualificações que possibilitam a uma pessoa ter uma performance superior em determinada situação de trabalho.

Tendo em vista estes questionamentos, entende-se que um estudo sobre gestão e avaliação da educação superior pode trazer contribuições significativas no sentido de abrir espaços para a realização de estudos envolvendo esta problemática. Neste sentido, torna-se relevante o foco nos egressos haja vista a grande contribuição que os mesmos podem proporcionar para a qualificação do ensino e a melhoria do processo de avaliação. De acordo com Schuch Jr. 
(1976), na Universidade Federal de Santa Maria, o movimento pela criação do Curso de Administração teve início dentro da então Faculdade de Ciências Econômicas. Um passo foi a criação, pela Universidade, do Instituto de Administração e Planejamento que, em 1965, realizou curso extraordinário para funcionários de prefeituras e administrativos da UFSM.

Devido à Reforma Universitária, em 1970, com a aprovação do Estatuto Geral da UFSM, o Curso passou a chamar-se Curso de Administração e a fazer parte do Centro de Ciências Jurídicas, Econômicas e Administrativas. O Curso foi reconhecido pelo Conselho Federal de Educação em 25 de junho de 1971, conforme Decreto n. 68.805, publicado no Diário Oficial da União, $\mathrm{n}^{\mathrm{o}} 120$, de 28 de junho de 1971 (NOGUEIRA, 1974). Após sua criação, em 1966, o currículo do curso foi modificado inúmeras vezes, originando várias versões curriculares, até que, em 1994, surge uma nova proposta curricular promovida pelo Curso de Administração da UFSM, atendendo aos anseios da comunidade acadêmica, da classe dos Administradores e ao cumprimento da determinação legal estabelecida pela Resolução n. 02, de 04 de outubro de 1993, do Conselho Federal de Educação.

A proposta trouxe um conteúdo de flexibilidades em sua estruturação, possibilitando uma maior duração ao currículo.

\section{PROCEDIMENTOS METODOLÓGICOS}

A pesquisa caracteriza-se como descritiva, já que pretende estudar e descrever características da realidade pesquisada. A pesquisa descritiva, segundo Gil (1999), possui como principal objetivo descrever as características de determinada população ou fenômeno ou o estabelecimento de relações entre as variáveis.

Quanto à abordagem, caracteriza-se por uma pesquisa predominantemente quantitativa, visto que se pretende medir de uma maneira precisa as respostas dos egressos quanto à sua situação e opinião em relação às questões da pesquisa. Para Hair et al. (2005), os dados quantitativos devem ser coletados por meio de várias escalas numéricas. As abordagens quantitativas são muito utilizadas quando possui problema de pesquisa ou modelos teóricos bem definidos.

A população alvo desta pesquisa foram os egressos do Curso de Administração da UFSM, formados no período de 2005 a 2009, que perfizeram um total de 359 elementos. A coleta de dados da pesquisa foi realizada por meio de questionários estruturados para análise das dimensões consideradas. Cada elemento da amostra recebeu dois questionários, enviados por email, acompanhados de 
um documento anexado com os necessários esclarecimentos e solicitação para que estes fossem respondidos e devidamente preenchidos.

No documento enviado por email, constava o número de matrícula do egresso e uma senha para que ele tivesse acesso ao link da página da UFSM na qual foram disponibilizados os questionários. Destes questionários, um deveria ser preenchido por aqueles que estavam atuando na profissão e outro por aqueles que não estavam.

O instrumento de coleta de dados foi uma réplica atualizada do original elaborado por Schuch Jr. (1976), com a inclusão de questões sobre competências baseadas no questionário proposto por Godoy et al., (2005). Ressalta-se que o tema competências não foi abordado no estudo de Schuch Jr. (1976).

O estudo de Schuch Jr. (1976) investigou o conhecimento de alguns aspectos da realidade profissional dos egressos do curso de Administração da UFSM e abordou, em função da relevância, as seguintes dimensões: o exercício da profissão, as características do mercado empresarial, a natureza das funções exercidas, o aproveitamento acadêmico e a situação do egresso e utilizou como método de coleta de dados o envio de questionários remetidos pelo correio $\mathrm{e}$ acompanhados de um envelope já subscritado e selado para facilitar o retorno da pesquisa, assim como de uma carta com os esclarecimentos para um preenchimento adequado.

O questionário I foi destinado aos egressos que estão atuando na profissão e está dividido em quatro partes: a primeira parte contém dados sobre a organização em que atua; a segunda parte, dados sobre sua atividade profissional, a terceira parte solicitou dados relacionados às competências e a quarta contém dados de base de natureza pessoal e do curso. Fazem parte deste questionário perguntas relacionadas com as competências e habilidades, propostas por Godoy et al. (2005), baseado nas propostas da Resolução CNE/CES 4/2005 para o Curso de Graduação em Administração. Esta terceira parte apresenta 27 variáveis referentes às competências investigadas.

Nesta parte específica sobre competências, foi utilizada uma escala tipo Likert, variando de 1 a 5 pontos, correspondendo, respectivamente, a discordo totalmente e concordo totalmente, para investigar as percepções dos alunos.

O questionário II foi dirigido para os egressos que não estavam atuando na profissão e contém duas partes: a primeira é composta por questões pessoais e a segunda solicita dados em relação à situação profissional.

A coleta de dados foi realizada de maio a julho de 2011 e obteve-se um retorno de 121 questionários. Os resultados obtidos baseiam-se na amostra de 121 respondentes - egressos do Curso de Administração da UFSM - assim, 
considerando o tamanho da amostra, as conclusões obtidas não podem ser generalizadas para todo o universo de egressos. Cabe ressaltar que, do total de respondentes, 57 dos egressos estão exercendo a profissão e 64 não estão.

Convém lembrar que apenas os egressos que estão exercendo a profissão responderam às informações a respeito das competências.

\section{RESULTADOS E DISCUSSÕES}

Esta seção primeiramente caracteriza os respondentes e, a seguir, apresentam-se os resultados relacionados às competências por meio da análise da confiabilidade dos dados, análise fatorial exploratória e conclusões sobre constructos e variáveis do modelo resultante. Ressalta-se que os dados obtidos no presente estudo são comparados aos resultados do estudo de Schuch Jr. (1976), a fim de comparar a realidade dos egressos em diferentes épocas e realidades.

\subsection{Caracterização dos respondentes}

Para caracterizar a amostra, foram coletados dados acerca do gênero, da faixa etária e do exercício ou não da atividade de administrador. No caso do respondente utilizar o questionário I, foi possível identificar que está desempenhando atividade de administrador, e os sujeitos da pesquisa que não estão exercendo a atividade de administrador responderam ao questionário II.

Os dados analisados demonstram que 47,10\% dos egressos estão exercendo a profissão e 62,89\% não estão. Já na pesquisa realizada por Schuch Jr. (1976), o índice de egressos que estavam desempenhando a função ficou em torno de $74 \%$.

Percebe-se que o percentual de egressos que não está exercendo a profissão no presente estudo é considerado elevado e bastante superior ao índice evidenciado no estudo de 1976, indicando dificuldade de colocação no mercado de trabalho pelos egressos do curso.

Nesse sentido, convém ressaltar os diferentes contextos socioeconômicos de ambas as pesquisas, tendo em vista que o presente estudo foi realizado 35 anos após o original de 1976. Para Martins (1989), o movimento para a formação profissional do administrador no Brasil começou a se definir na década de quarenta, quando a economia brasileira deixou de ser essencialmente agrária e iniciou-se a expansão dos setores industriais e de serviços, acentuando a necessidade de mão de obra qualificada. Segundo Schuch Jr. (1976), foi em 1954, com a criação da EAESP, que surgiu o primeiro currículo de Administração, influenciando, assim, as instituições de ensino superior, que passariam a ofer- 
ecer o curso no país. Dessa forma, na realidade de 1976, ainda eram poucos os cursos de Administração e, a partir da década de 1990, ocorre um considerável aumento na oferta de tais cursos. De acordo com o Censo do Ensino Superior, realizado pelo Inep, em 2008, a expansão das Instituições de Ensino Superior (IES) em Administração, no Brasil, é expressiva a partir da segunda metade da década de 1990, chegando, em 2008, a 2.252 IES, envolvendo 872.265 alunos matriculados. Os egressos do presente estudo estão inseridos nessa realidade de expansão dos cursos de Administração no Brasil, o que caracteriza uma maior oferta de profissionais no mercado de trabalho.

Também convém destacar as mudanças ocorridas no mercado de trabalho, que tem se tornado cada vez mais competitivo e exigido dos profissionais uma gama de competências e habilidades. Para Rojo e Kasper (2009), o mercado de trabalho está passando por profundas transformações em todos os níveis, sendo que o bacharel em Administração deve estar preparado para buscar os conhecimentos necessários, além de identificar quais habilidades lhes serão exigidas neste mercado tão tumultuado e competitivo.

Rojo e Kasper (2009) ainda afirmam que, em décadas passadas, a qualificação profissional garantia aos indivíduos as condições para competirem no mercado de trabalho. Contudo, atualmente, o profissional de sucesso não é mais aquele especializado em determinado assunto e, sim, aquele que possui uma visão globalizada para atender a um consumidor exigente.

A dificuldade de inserção no mercado de trabalho também pode estar relacionada com o processo de ensino-aprendizagem. Tendo em vista que não há uma política de acompanhamento dos egressos de cursos superiores, bem como não são elencadas as dificuldades enfrentadas pelos ex-alunos, as IES não podem promover mudanças necessárias em seus currículos e processos de ensino-aprendizagem, o que vai ao encontro das ideias de Lousada e Martins (2005) ao afirmarem que mudanças a fim de acompanhar os egressos e as dificuldades enfrentadas no mercado de trabalho podem preencher as lacunas que existem entre a formação acadêmica do aluno e as reais necessidades de qualificação exigidas pelo mercado de trabalho.

Quanto ao gênero dos egressos, pode-se observar que 50,88\% dos respondentes que exercem a profissão são do sexo feminino e 49,12\% do sexo masculino. Este resultado destaca um percentual equilibrado entre homens e mulheres, não sendo possível uma comparação com a pesquisa original (SCHUCH JR., 1976), pois esta variável não foi investigada.

Trata-se de um grupo jovem, com um percentual médio de 54,39\% dos egressos na faixa de 26 a 30 anos, seguidos por $26,32 \%$ com idade até 25 anos, 
$12,28 \%$ com idade entre 31 a $35,5,26 \%$ estão entre 36 e 40 anos e $1,75 \%$ com mais de 46 anos. Observou-se que, em ambas as pesquisas, destacou-se a faixa etária entre 26 e 30 anos.

Verificou-se que a cidade com o maior percentual de residência dos egressos é Santa Maria- RS, com 43,80\%, seguida de Porto Alegre - RS, com 14,00\%, sendo que esta situação também se caracterizou na pesquisa de Schuch Jr. (1976). Constatou-se também que em torno de 50\% dos egressos do curso estavam atuando em empresas industriais e de prestação de serviços e, na cidade, o predomínio era de empresas comerciais. O estudo atual exibe resultados próximos à pesquisa do mesmo autor, com egressos atuando em empresas de prestação de serviços $(36,84 \%)$ e também em instituições de ensino (28,07\%).

Realizando-se cruzamento dos resultados do perfil dos egressos com o gênero, pode-se observar sobre as atividades profissionais que, quanto à natureza da organização, nas empresas de prestação de serviços, prevalecem as mulheres (40,35\%) em relação aos homens (31,58\%) nas empresas. Os homens destacam-se na atuação em empresas comerciais $(10,53 \%)$ e industriais $(7,02 \%)$ comparados às mulheres, que registram 7,02\% com atuação em empresas comerciais e 3,51\% em industriais. Com relação à atuação na esfera pública, destaca-se uma maior inserção dos egressos do gênero feminino $(21,43 \%)$ em relação ao gênero masculino (12,50\%) em instituições federais. Ressalta-se a atuação dos egressos em instituições de ensino, nas quais atuam 19,30\% das mulheres e $8,77 \%$ dos homens.

Com relação à natureza da função exercida pelos administradores, evidenciou-se que as mulheres atuam, em sua maioria, em atividades técnicas $(21,43 \%)$, seguidas de atividades de direção $(19,64 \%)$, enquanto os homens desempenham, em sua maioria, atividades de direção $(19,64 \%)$, seguidas de atividades técnicas $(17,86 \%)$. Observou-se que, quanto à área de atuação principal, as mulheres atuam majoritariamente na área gestão de pessoas $(17,39 \%)$ e os homens na área de gestão financeira/orçamento $(8,70 \%)$. No que se refere à preferência para qualificação futura, o sexo feminino prioriza o mestrado $(21,82 \%)$, enquanto que os resultados da pesquisa evidenciam que os homens têm preferência em cursos de curta duração (14,55\%).

A seguir, apresentam-se os resultados referentes às competências dos egressos.

\subsection{Competências dos egressos}

No que se refere às competências, apenas os egressos que estão exercendo a profissão responderam as questões relacionadas a este aspecto. 
Com relação à dimensão competências, inicialmente foi realizada a análise da consistência interna dos constructos por meio do coeficiente Alpha de Cronbach. A análise verifica se os indicadores convergem ou estão relacionados entre si, refletindo o constructo.

A Tabela 2 mostra a dimensão, o número de itens relacionados em cada constructo e o valor do alpha. Um instrumento é classificado como tendo confiabilidade apropriada quando o valor é de pelo menos 0,70. Em pesquisas exploratórias, são aceitáveis valores de até 0,60 (HAIR et al., 2005). Apesar de a confiabilidade ter sido realizada na dimensão e nos constructos, a pesquisa considera o valor 0,874 da dimensão.

Tabela 2 - Confiabilidade interna (Alpha de Cronbach)

\begin{tabular}{lrr}
\hline Dimensão - Constructo & Itens & a de Cronbach \\
\hline Competência & 27 & 0,874 \\
Solução de problemas & 7 & 0,781 \\
Comunicação & 6 & 0,608 \\
Técnico profissional & 6 & 0,596 \\
Social & 8 & 0,752 \\
\hline
\end{tabular}

Fonte: Dados da pesquisa

A dimensão competências captura informações sobre a competência para a solução de problemas, para comunicação, para aplicar o conhecimento técnico profissional e para a gestão social em 27 variáveis distribuídas em quatro constructos na dimensão. Na análise fatorial, o KMO indicou índice de 0,642, e o teste de esfericidade de Bartlett's foi significativo a $(p=0,000)$. Esses resultados indicam que existe correlação entre as variáveis e adequação dos dados para a realização da análise fatorial.

Usando o método de rotação varimax com normalização Kaiser, na primeira e segunda análise, variáveis que retornaram comunalidade abaixo de 0,5 foram retiradas do modelo. Na terceira análise em sete interações, a matriz fatorial rotacionada mostrou que, dos vinte sete itens, somente dezesseis permanecem na dimensão competências e são explicados em 63,73\% em quatro constructos.

Os fatores/constructos foram reorganizados de forma diferente da proposta do estudo. A matriz da variância total explicada mostrou que os fatores extraídos explicam, respectivamente, a variância de $20,42 \%, 15,98 \%, 15,07 \%$ e $12,26 \%$ e totalizam $63,73 \%$. 
A matriz dos componentes fatoriais rotacionados fornece os valores das cargas fatoriais e agrupa as variáveis conforme fatores relacionados na matriz de variância total explicada. Assim, o resultado da Análise Fatorial Exploratória (AFE) forma um novo agrupamento de variáveis na dimensão analisada conforme dados dos respondentes (Quadro 1).

\section{Quadro 1 - Análise fatorial exploratória da dimensão competência}

\begin{tabular}{|c|c|c|}
\hline Constructos & Itens & $\begin{array}{l}\text { Carga } \\
\text { Fatorial }\end{array}$ \\
\hline \multirow{5}{*}{$\begin{array}{l}\text { Fator 1: Padrões e } \\
\text { Valores }\end{array}$} & CP48 - Respeitar o próximo & 0,848 \\
\hline & CP49 - Ter autocrítica & 0,827 \\
\hline & $\begin{array}{l}\text { CP38 - Buscar o aperfeiçoamento contínuo da qualidade } \\
\text { dos trabalhos sob minha responsabilidade. }\end{array}$ & 0,740 \\
\hline & $\begin{array}{l}\text { CP45 - Levar em conta os valores éticos na minha } \\
\text { atuação profissional. }\end{array}$ & 0,706 \\
\hline & $\begin{array}{l}\text { CP30 - Comunicar-me na forma escrita e verbal de } \\
\text { maneira clara e objetiva. }\end{array}$ & 0,608 \\
\hline \multirow{4}{*}{$\begin{array}{l}\text { Fator 2: Adaptação e } \\
\text { Negociação }\end{array}$} & $\begin{array}{l}\text { CP27 - Tomar decisões a partir da identificação e } \\
\text { análise dos vários aspectos envolvidos nas situações } \\
\text { de trabalho. }\end{array}$ & 0,777 \\
\hline & $\begin{array}{l}\text { CP36 - Manter-me produtivo apesar dos obstáculos e } \\
\text { pressões inerentes às situações de trabalho. }\end{array}$ & 0,775 \\
\hline & $\begin{array}{l}\text { CP35 - Buscar soluções originais e criativas, de forma } \\
\text { inovadora e viável. }\end{array}$ & 0,610 \\
\hline & $\begin{array}{l}\text { CP41- Adaptar-se às novas situações e/ou pressões } \\
\text { de trabalho, promovendo esforços de negociação para } \\
\text { obtenção de resultados satisfatórios. }\end{array}$ & 0,595 \\
\hline \multirow{4}{*}{ Fator3: Conhecimento } & $\begin{array}{l}\text { CP43 - Realizar tarefas e atividades próprias de } \\
\text { consultoria em gestão e administração. }\end{array}$ & 0,747 \\
\hline & CP42 - Elaborar e implementar projetos em organizações. & 0,728 \\
\hline & $\begin{array}{l}\text { CP39 - Agir buscando atender as demandas críticas, } \\
\text { com senso de responsabilidade pelos direitos e deveres } \\
\text { dos indivíduos. }\end{array}$ & 0,654 \\
\hline & $\begin{array}{l}\text { CP26 - Transferir e aplicar conhecimentos técnicos para } \\
\text { resolver problemas em situação de trabalho. }\end{array}$ & 0,543 \\
\hline \multirow{3}{*}{$\begin{array}{l}\text { Fator 4: Técnico } \\
\text { Profissional }\end{array}$} & $\begin{array}{l}\text { CP31 - Raciocinar de forma lógica e analítica utilizando } \\
\text { embasamento matemático. }\end{array}$ & 0,830 \\
\hline & $\begin{array}{l}\text { CP32 - Raciocinar de forma lógica e analítica } \\
\text { estabelecendo relações formais e causais entre os } \\
\text { fenômenos produtivos administrativos e de controle. }\end{array}$ & 0,643 \\
\hline & $\begin{array}{l}\text { CP37-Pesquisar e buscar os conhecimentos necessários } \\
\text { ao aprofundamento e atualização nas áreas funcionais } \\
\text { de meu interesse. }\end{array}$ & 0,551 \\
\hline
\end{tabular}

Fonte: Dados da pesquisa 
Para confirmar a confiabilidade dos dados, a Tabela 3 mostra o resultado da análise de Alpha de Cronbach após a AFE. Conforme descrito anteriormente, mesmo que um constructo apresente um alpha baixo, para pesquisa exploratória são admissíveis valores até 0,60 (HAIR et al., 2005). Nesta pesquisa, a confiabilidade considerada está na dimensão analisada e, portanto, o valor resultante de 0,809 fornece qualidade aos dados.

Tabela 3 - Confiabilidade interna (Alpha de Cronbach) após AFE

\begin{tabular}{lrr}
\hline Dimensão -Constructo & Itens & $\boldsymbol{\alpha}$ de Cronbach \\
\hline Competência & 16 & 0,809 \\
Fator 1 - Padrões e Valores & 5 & 0,814 \\
Fator 2 - Adaptação e Negociação & 4 & 0,770 \\
Fator 3 - Conhecimento & 4 & 0,708 \\
Fator 4 - Técnico-Profissional & 3 & 0,584 \\
\hline
\end{tabular}

Fonte: Dados da pesquisa

Após a análise do Alpha de Cronbach, percebe-se um novo agrupamento de variáveis que não confirmam o agrupamento encontrado no estudo de Godoy et al. (2005). Nesta pesquisa, o novo agrupamento de variáveis na dimensão analisada nos remete à interpretação dos fatores obtidos com outra nomeação e características (Quadro 2).

\section{Quadro 2 - Descrição dos fatores}

\begin{tabular}{|l|l|}
\hline Fator 1 - Padrões e Valores & $\begin{array}{l}\text { Respeitar o próximo, ser autocrítico, buscar aperfeiçoamento } \\
\text { contínuo, considerar os valores éticos da profissão e comunicar- } \\
\text {-se de forma clara e objetiva }\end{array}$ \\
\hline Fator 2 - Adaptação e & $\begin{array}{l}\text { Tomar decisões a partir da análise dos vários aspectos nas } \\
\text { mudanças de processos de trabalho, manter-se produtivo ape- } \\
\text { sar dos obstáculos, buscar soluções originais e criativas bem } \\
\text { como adaptar-se às novas situações e/ou pressões de trabalho }\end{array}$ \\
\hline Fator 3 - Conhecimento & $\begin{array}{l}\text { Realizar tarefas e atividades de consultoria em gestão e admi- } \\
\text { nistração, elaborar e implementar projetos, respeitar as pessoas } \\
\text { com senso de responsabilidade pelos direitos e deveres e, } \\
\text { considera também transferir e aplicar conhecimentos técnicos } \\
\text { para solução de problemas }\end{array}$ \\
\hline Fator 4 - Técnico- & $\begin{array}{l}\text { Raciocinar de forma lógica e analítica com embasamento } \\
\text { matemático e estabelecer relações formais e causais entre os } \\
\text { fenômenos produtivos. }\end{array}$ \\
\hline
\end{tabular}

Fonte: Dados da pesquisa 
O novo agrupamento das questões convergiu em quatro fatores: padrões e valores, adaptação e negociação, conhecimento e técnico profissional. Convém ressaltar que o conjunto considerado mais relevante, do ponto de vista dos egressos, refere-se às competências relativas a padrões e valores (Fator 1), uma vez que este fator explica sozinho cerca de $20 \%$ da variância total dos dados.

$\mathrm{O}$ resultado pode sugerir que a expectativa das Diretrizes Curriculares Nacionais propostas para o Curso de Administração da UFSM esteja atendendo à perspectiva e estão sendo desenvolvidas durante a graduação. Com base nestas informações, pode-se dizer que as competências esperadas dos egressos investigados aproximam-se daquelas estabelecidas por Zarifian (2003) e Fleury e Fleury (2001). Convém recordar que Zarifian (2003) propõe quatro áreas de competências - competências da profissão ou técnicas, organizacionais, de inovação, relacionais - e que Fleury e Fleury definem três blocos: competências de negócio, técnico-profissionais e sociais. É importante destacar que competência é uma inteligência prática, aplicada às situações reais, que se apoia em conhecimentos adquiridos, os quais se transformam na medida em que as ações são desenvolvidas (ZARIFIAN, 2003). Os resultados da pesquisa foram percebidos no exercício da função de administradores, onde ocorre a percepção real das competências adquiridas na prática.

Continuando a discussão das competências, a Tabela 4 apresenta as respostas dos egressos. Demonstra-se o quanto o aluno concorda ou discorda de que as tenha desenvolvido durante a graduação, e as questões foram ordenadas em ordem decrescente, possibilitando visualizar as assertivas em que há maior concordância.

As respostas estão agrupadas em graus de frequência, considerando que elas se encontram em escalas de discordância/concordância: o primeiro grau DT (Discordo Totalmente); o segundo grau DP (Discordo Parcialmente); o terceiro grau NC-ND (Não Concordo - Não Discordo); o quarto grau CT (Concordo Totalmente) e o quinto grau CP (Concordo Parcialmente).

Os resultados apresentados na Tabela 4 evidenciam que, na percepção dos egressos, o maior índice das competências adquiridas concentram-se nos fatores 1 (Padrões e Valores) e fator 4 (Técnico Profissional). Cabe ressaltar que os índices de grande discordância (DT) apresentaram-se baixos e sempre inferiores às demais escalas.

Concluídas as análises dos resultados sobre as competências e com base nas informações obtidas a partir dos dados coletados, pode-se concluir que a pesquisa atingiu seu objetivo, ao verificar que o curso contribui para o desenvolvimento das competências que o currículo pretendia. 


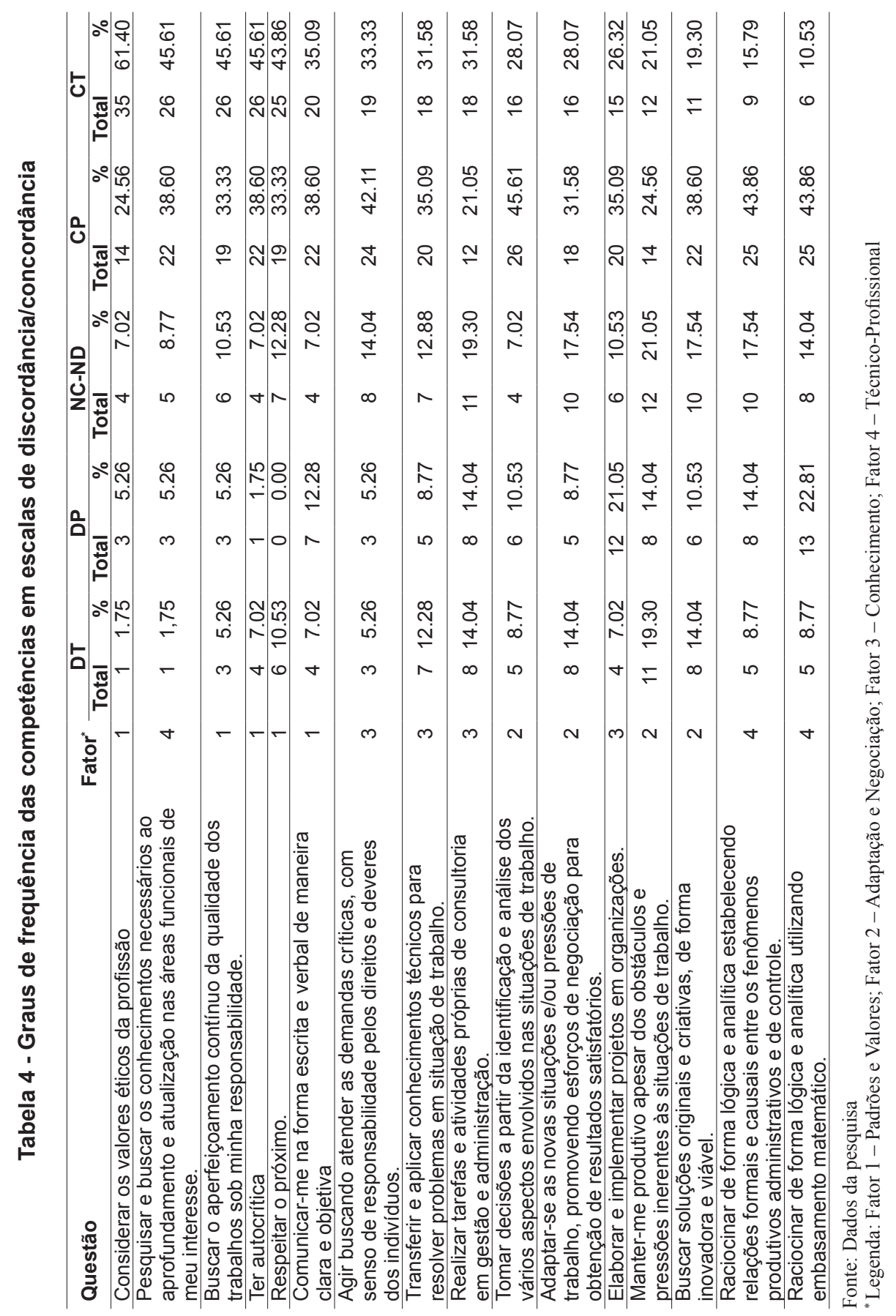




\section{CONSIDERAÇÕES FINAIS}

O conhecimento do mercado de trabalho da profissão de administrador exige uma pesquisa bastante ampla e de difícil realização. Com este trabalho, acreditase que um segundo passo foi dado no sentido de verificar as dificuldades que enfrentam os egressos do curso de Administração da UFSM para sua inserção no mercado de trabalho. O primeiro passo foi verificado na pesquisa realizada por Schuch Jr. (1976), intitulada Formação de Administradores e Mercado de Trabalho. A avaliação realizada neste estudo constatou que a maioria dos egressos do curso de Administração da UFSM não está desempenhando a profissão para a qual foi preparada, mas, na pesquisa realizada em 1976, o índice de egressos que estavam desempenhando a função ficou em torno de $74 \%$.

A partir das informações levantadas, evidencia-se a necessidade de um levantamento mais convergente com a realidade do mercado de trabalho para o qual o curso está preparando seus alunos. $\mathrm{O}$ fato observado relacionado com a dificuldade dos egressos ao serem inseridos no campo profissional serve como alerta para os cursos no sentido de identificar possíveis falhas e propor melhorias nas suas estruturas, sendo que uma delas pode estar vinculada ao currículo. Esta melhoria só pode ocorrer no momento em que as IES passem a acompanhar o aproveitamento de seus egressos no mercado de trabalho, e um destes mecanismos seria utilizar políticas voltadas à gestão de egressos. Outro motivo do não exercício da profissão pode ser em decorrência da expressiva expansão das IES em Administração no Brasil, de acordo com o Censo do Ensino Superior realizado pelo INEP em 2008, que envolveu 872.265 alunos matriculados e, na década de 70 , o número de matriculados estava em torno de 134.742 alunos (INEP, 2009).

Além da expansão dos cursos de Administração que formam os bacharéis, também está havendo uma oferta significativa de cursos de Tecnólogos em diversas áreas da Administração, que possuem duração mais curta que os bacharelados e levam em conta as demandas específicas que a economia apresenta e, assim, forma profissionais de acordo com a exigência do mercado.

A pesquisa realizada por Schuch Jr. (1976) constatou que em torno de 50\% dos egressos do curso estavam atuando em Santa Maria - RS, fato que se confirmou no estudo atual, correspondendo a 26,32\%. No estudo de Schuch Jr. (1976), os egressos estavam atuando em empresas industriais $(36,84 \%)$ e de prestação de serviços $(36,84 \%)$ e, na cidade, o predomínio era de empresas comerciais. $\mathrm{O}$ estudo atual exibe resultados próximos ao da pesquisa do mesmo autor, com egressos atuando em empresas de prestação de serviços $(36,84 \%)$ e também em instituições de ensino $(28,07 \%)$. Cabe destacar que a concentração dos egres- 
sos em instituições de ensino deve estar relacionada ao fato de Santa Maria atualmente destacar-se na região, no estado e no país como cidade com funções relacionadas principalmente à prestação de serviços, comercial e educacional. Destaca-se também no setor médico hospitalar, rodoviário e militar policial.

Uma pesquisa realizada pelo CFA (2006) em relação ao mercado de trabalho para o Administrador, nos próximos 5 anos, evidencia que ele está concentrado em Consultoria Empresarial, Instituições Financeiras, Industrial, Terceiro Setor e Turismo e Lazer. Com base nestas informações, observa-se uma dificuldade em oportunizar um ensino mais prático e vivencial para os acadêmicos em função das características da região, que não oferta estas áreas de atuação apontadas pela pesquisa.

O estudo está focado na percepção dos alunos em conseguir desenvolver os conhecimentos, as habilidades e as atitudes sugeridas pelas diretrizes curriculares durante a graduação do curso de Administração da UFSM. Com o propósito de investigar estas informações, foram analisadas informações a respeito das competências dos egressos que estão exercendo a profissão. $\mathrm{Na}$ perspectiva dos alunos, a análise descritiva mostra alto grau de concordância nas competências propostas pela DCN. Já os resultados da análise fatorial não confirmam o agrupamento encontrado no estudo de Godoy et al.(2005).

Nesta pesquisa, observou-se um novo agrupamento, pois as questões foram agrupadas em quatro fatores: padrões e valores, adaptação e negociação, conhecimento e técnico profissional. O resultado pode sugerir que a expectativa das Diretrizes Curriculares Nacionais propostas para o Curso de Administração da UFSM esteja atendendo à perspectiva e estão sendo desenvolvidas durante a graduação. Os resultados da pesquisa foram percebidos no exercício da função de administradores, na qual ocorre a percepção real das competências adquiridas na prática.

Como principal dificuldade na realização do presente estudo, ressalta-se a de contato com os egressos. Desse modo, a não existência de dados organizados e de fácil utilização dificultou o contato com os egressos, o que pode ter ocorrido em função da falta de tradição acadêmica no Brasil em acompanhar seus ex-alunos. Esse fato não acontece em universidades de países desenvolvidos, principalmente da Europa e dos Estados Unidos, nas quais o relacionamento com o alumni (ex-aluno) é encarado com muito profissionalismo, sendo que, nos departamentos de Desenvolvimento Institucional destas universidades, há áreas de alumni relations que solidificam o relacionamento entre a universidade e os seus egressos (CASSIMIRO, 2005; MATIAS-PEREIRA; KRUGLIANSKAS, 2005). 
Para um maior aprofundamento do estudo, sugere-se a realização de pesquisas futuras envolvendo um período maior de abrangência, já que este estudo foi baseado no retorno dos egressos de 2005 a 2009, e a pesquisa anterior foi feita em 1976 e não abordou a percepção dos alunos em relação às competências adquiridas durante a graduação.

O estudo apresentou algumas limitações metodológicas decorrentes do número dos egressos participantes da pesquisa. Tendo em vista o retorno de questionários, a amostra caracteriza-se como não probabilística, o que reduz o âmbito de aplicação dos estudos, não se podendo inferir que esses comportamentos revelados identificam todo o universo dos egressos. Apesar disso, as conclusões do estudo são relevantes. As análises são válidas para a descrição e a avaliação do perfil dos egressos do curso de Administração da UFSM que estão exercendo a profissão e para os que ainda almejam a inserção no mercado de trabalho.

Espera-se que este estudo não só contribua para a melhoria do ensino de Administração na UFSM mas também para o conhecimento do mercado de trabalho desta área, que é uma das que têm mais crescido no Brasil. Poderá servir ainda como um referencial útil para outras IES que pretendem buscar o conhecimento da realidade de seus egressos.

\section{REFERÊNCIAS}

BARTALOTTI, Otávio; MENEZES-FILHO, Naércio. a relação entre o desempenho da carreira no mercado de trabalho e a escolha profissional dos jovens. Revista de Economia Aplicada, Ribeirão Preto, v. 11, p. 487-506, 2007.

BITENCOURT, Cláudia Cristina.Competência gerencial e aprendizagem nas organizações. São Leopoldo: Unisinos, 2005.

BITENCOURT, Cláudia Cristina; KLEIN, Maria Josefina. Desenvolvimento de competências: a percepção dos egressos do curso de graduação em administração. In: ENCONTRO NACIONAL DOS PROGRAMAS DE PÓS-GRADUAÇÃO EM ADMINISTRAÇÃO - EnANPAD,31., 2007, Rio de Janeiro. Anais... Rio de Janeiro: ANPAD, 2007.

BOYATZIS, R. E. The competent Manager. New York: John Wiley \& Sons, 1982 
BRASIL. Resolução CNE/CEB no 04/99, de 5 de outubro de 1999. Institui as Diretrizes Curriculares Nacionais para a Educação Profissional de Nível Técnico, baseada no Parecer CNE/CEB, no 16/99, de 5 de outubro de 1999.

BRASIL. Leis. Resolução nº 4 de julho de 2005. Institui as Diretrizes Curriculares Nacionais dos Cursos de Graduação em Administração, bacharelado, e dá outras providências.

CASTRO, Claudio de Moura. O ensino da administração e seus dilemas: notas para debates. Revista de Administração de Empresas, São Paulo, v. 21, n.3, p. 58-61, jul./set, 1981.

CONSELHO FEDERAL DE ADMINISTRACAO. Perfil do administrador e mercado de trabalho: pesquisa nacional. Brasília: CFA, 2006.

\section{COUVRE, M. L. M. A formação e a ideologia do administrador de} empresas. São Paulo: Cortez,1991.

DUTRA, Joel Souza. Competências: conceitos e instrumentos para a gestão de pessoas na empresa moderna. São Paulo: Atlas, 2008.

DUTRA, Joel Souza, HIPÓLITO, José Antonio Monteiro; SILVA, Cassiano Machado. Gestão de Pessoas por Competências: o caso de uma empresa no setor de telecomunicações. In: ENCONTRO NACIONAL DOS PROGRAMAS DE PÓS-GRADUAÇÃO EM ADMINISTRAÇÃO EnANPAD, 1998, Natal. Anais...Natal: ANPAD, 1998.

FLEURY, Afonso; FLEURY, Maria Teresa Leme. Estratégias empresariais e formação de competências: um quebra-cabeça caleidoscópico da indústria brasileira. São Paulo: Atlas, 2007.

FLEURY, Afonso; FLEURY, Maria Tereza Leme. Construindo o Conceito de Competência. Revista de Administração Contemporânea, Curitiba, v. 5, n. especial, 2001.

GIL, Antonio Carlos. Métodos e técnicas de pesquisa social. São Paulo: Atlas, 1999.

GODOY, Arilda Schmidt et al. Competências adquiridas durante os anos de graduação: um estudo de caso a partir das opiniões de alunos formandos de um curso de Administração de Empresas. In: ENCONTRO NACIONAL 
DOS PROGRAMAS DE PÓS-GRADUAÇÃO EM ADMINISTRAÇÃO EnANPAD, 29., 2005, Brasília. Anais... Brasília: ANPAD, 2005.

GUBIANI, Juçara Salete. Modelo para diagnosticar a influência do capital intelectual no potencial de inovação nas universidades. Tese (Doutorado) - Centro Tecnológico. Programa de Pós-Graduação em Engenharia e Gestão do Conhecimento, - Universidade Federal de Santa Catarina, Florianópolis, 2011.

HAIR, Jr. Joseph. F.; BABIN, Barry; MONEY, Arthur. H.; SAMOUEL, Phillip. Fundamentos de métodos de pesquisa em administração. Porto Alegre: Bookman, 2005.

INEP - Instituto Nacional de Estudos e Pesquisas Educacionais. Sinopse Estatística da Educação Superior. Brasília, DF, 2009.

LACOMBE, F., HEILBORN, G. Administração: princípios e tendências. São Paulo: Saraiva, 2002.

LE BOTERF, Guy. Desenvolvendo a competência dos profissionais. Porto Alegre: Artmed, 2003.

LOUSADA, A. C. Z. ; MARTINS, G. A. Egressos como fonte de informação a gestão dos cursos de Ciências Contábeis. Revista Contabilidade \& Finanças, São Paulo, v. 1, n. 37, p. 73-84, 2005.

MARTINS. Carlos Benedito. Surgimento e expansão dos cursos de administração no Brasil. Educação \&Sociedade, São Paulo, n. 34, dez. 1989.

MATIAS-PEREIRA, J; KRUGLIANSKAS, I. Gestão de inovação: a lei de inovação tecnológica como ferramenta de apoio às políticas industrial e tecnológica do Brasil. RAE, São Paulo, v. 4, n. 2, 2005.

McCLELLAND, David C. Testing for competence rather than intelligence. American Psychologist, Washington, p. 1-14, jan. 1973.

McLagan, P. Great ideas revisited: Creating the future of HRD. Training and Development, Malden, v. 50, n. 1, p. 60-65, 1996.

NOGUEIRA, Eduardo P. P. Discurso proferido por ocasião da abertura da Semana do Administrador. Santa Maria: UFSM, 2 set. 1974. 
NUNES, Simone Costa; BARBOSA, Allan Claudius Queiroz. A inserção das competências no curso de graduação em Administração: um Estudo em universidades brasileiras. In: ENCONTRO NACIONAL DOS PROGRAMAS DE PÓS-GRADUAÇÃO EM ADMINISTRAÇÃO EnANPAD, 27., 2003, Atibaia. Anais... Atibaia, 2003.

PERRENOUD, Philippe. Construir as competências desde a escola. Porto Alegre: Artes Médicas Sul, 1999.

ROJO, C. A.; KASPER,D. Evolução profissional do egresso do curso de Administração da Unioeste de Cascavel. Revista TECAP, Cascavel, v. 3, n. 03, p. 59-64, 2009.

SCHUCH JR., Vitor Francisco. Formação de administradores e mercado de trabalho. Um estudo dos egressos do Curso de Administração da UFSM e o mercado de trabalho. Dissertação (Mestrado em Administração) UFRGS, 1976. Porto Alegre: UFRGS, 1978.

SPENCER, L. M.; SPENCER, S. M. Competence at work: models for superior performance. New York: John Wiley \& Sons, 1993.

ZARIFIAN, Philippe. A gestão da e pela competência. Rio de Janeiro: Centro Internacional para Educação, Trabalho e Transferência de Tecnologia, 1996.

ZARIFIAN, Philippe. Objetivo competência: por uma nova lógica. São Paulo: Atlas, 2001.

ZARIFIAN, Philippe. O modelo da competência: trajetória histórica, desafios atuais e propostas. Trad Eric R. R. Heneault. São Paulo: Senac, 2003.

WOOD JR, Thomaz. Pop-management: MBAs no Brasil. Relatório de pesquisa. São Paulo, 2002. Disponível em: <http:/www.edudatabrasil.inep. gov.br/>. Acesso em: $12 \mathrm{dez} 2010$.

ERRATA:

No artigo: GESTÃO DE COMPETÊNCIAS PROFISSIONAIS NA FORMAÇÃO DE ADMINISTRADORES, publicado no número 1, volume 19, da Revista Avaliação, na página 129, no nome da autora MARia de Lourdes Severo ReGl onde se lê REGI, leia-se REGIO. 